\section{Original Research}

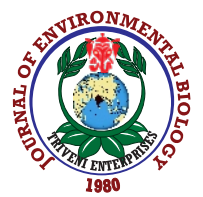

DOI : http://doi.org/10.22438/jeb/41/6/MRN-1281

\title{
Performance studies on jumping behaviour in froglets exposed to commercial grade malathion
}

\author{
K. Kulkarni and S.V. Krishnamurthy* \\ Department of PG Studies and Research in Environmental Science, Kuvempu University, Shankaraghatta-577 451, India \\ *Corresponding Author Email : svkrishnamurthy@gmail.com
}

Paper received: 16.09 .2019

Revised received: 28.02 .2020

Accepted: 05.06.2020

\section{Abstract}

Aim: Behavioural changes of an organism are used as an indicator to assess the impact of neurotoxic compounds. Jumping performance of newly emerged froglets exposed to malathion at their tadpole stage was studied.

\begin{abstract}
Methodology: Tadpole groups were exposed to 1226 , 2453 and $6133 \mu \mathrm{gl}^{-1}$ malathion in laboratory mesocosms. When they emerged as froglet, their jumping performance was studied
\end{abstract}

Results: As malathion is an AChE inhibitor and produces negative effect on survival of tadpoles, we anticipated increased malathion exposure could result in reduction of jumping distance in metamorphs. However, as compared to control, the jumping distance increased with malathion concentrations and showed significant

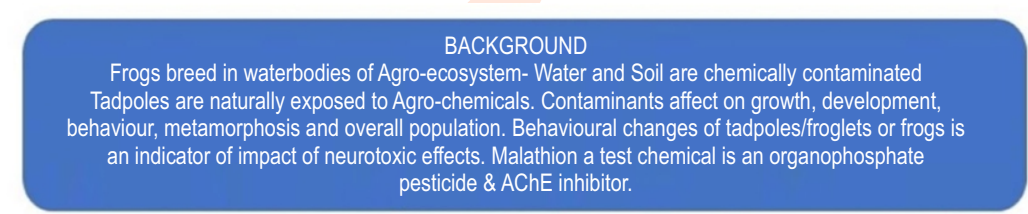

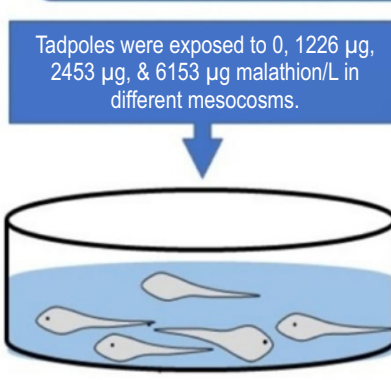

Laboratory Mesocosm

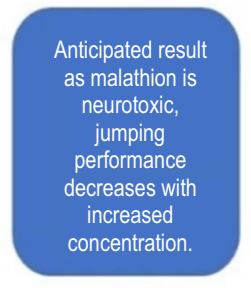

Froglets treated with different concentrations of pesticides were made to jump and jumping performance was recorded.

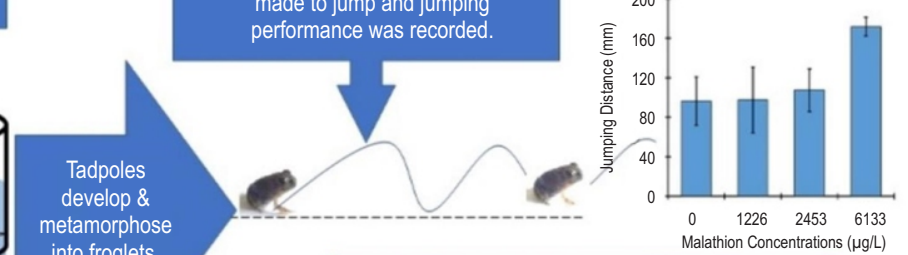

RESULT - Jumping performance at low concentrations was comparable to control concentrations was comparable to control
up but at high concentration it increased - Reas group but at high concentration it inc
to be investigaged

increase in the individuals treated with the highest concentration of malathion $\left(\mathrm{LC}_{25} ; \mathrm{F}_{3221}=11.41, \mathrm{p}=0.0001\right)$.

Interpretation: Malathion is toxic to tadpoles; however, it could result in concentration dependent jumping performance within the tested concentrations. Several other factors like tadpole density, temperature of the media, pesticide tolerance may act as determining factor, which requires further investigations.

Key words: Froglets, Jumping performance, Malathion, Metamorphs

How to cite : Kulkarni, K. and S.V. Krishnamurthy: Performance studies on jumping behaviour in froglets exposed to commercial grade malathion. J. Environ. Biol., 41, 1450-1454 (2020). 


\section{Introduction}

Amphibians are sensitive to environmental stress both during their larval and adult stages (Venturino et al., 2003). The excessive usage of agrochemicals is one among the various causes for declining amphibian population (Hegde and Krishnamurthy, 2014). In the recent decades, there is an increase in application of agrochemicals (Nataraj and Krishnamurthy, 2012). As a result, the agricultural sites are contaminated (Krishnamurthy et al., 2006; Mann et al., 2009). Several studies show that these agrochemicals affect the health of various nontarget organisms including amphibians living in the agroecosystems (Relyea, 2009). The biological effects of agrochemicals are chronic, detrimental and alter the biology of amphibians (Mann et al., 2009; Lajmanovich et al., 2019). Biomarker studies and other invasive methods dealing with the changes in the biology of frogs/tadpoles exposed to agrochemicals have revealed chromosomal aberrations, changes in the RBC structure etc., (Hegde and Krishnamurthy 2014; Josende et al., 2015). Since the amphibian larvae are under risk due to desiccation of water bodies, chronic exposure studies are important (Vasconcelos et al., 2016).

At chronic exposures to agrochemicals, the effects are apparent after a lapse of time and influence on the normal behaviour of the survivors (Shuman-Goodier, 2016). Behavioural changes in an organism are known to produce indirect effects on the entire community structure induced by altering species interactions. Therefore, it has been opined that, there is a need to integrate behavioural changes with the concept of community ecology to the field of toxicology to improve the evaluation of toxic effect of pesticides (Söffker and Tyler, 2012). Further, understanding the latent effect of exposure to contaminants on larval amphibians is important to understand behaviour (LeeJenkins and Robinson, 2018). Further, incorporating the measures of behaviour and to link the effect of internal physiology to the external environment is considered as a pivotal measure (Shuman-Goodier, 2016). Earlier researchers have reported altered behaviour like swimming and feeding among the larval amphibians (Sievers et al., 2019), however, very few studies have been conducted on the latent effect of agro-chemicals on the behaviour of adult amphibian populations. Thus, the behavioural responses on locomotion of froglets, which were previously exposed to malathion (organophosphate insecticide) at environmentally realistic concentrations at their tadpole stages were assessed to understand the performance changes. Malathion has a short half-life in water (0.2-21 weeks) depending on the pH (Mulla etal., 1981).

The concentration of malathion in most of surface water and sediment of agro-ecosystems of India range between 0.699 and $2.618 \mathrm{\mu gl}^{-1}$ (Rao and Pillala, 2001; Sankararamakrishnan et al., 2005). The larvae and adults of Indian Cricket frog (Fejervarya limnocharis) are commonly found in the rice paddy fields across South and Southeast Asia. As organophosphate insecticides are AChE inhibitors which affect the tadpole behaviour (Zala and
Penn, 2004; Krishnamurthy and Smith, 2010) and disrupt endocrine activity (Lal et al., 2013; David and Kartheek, 2015), we anticipated that chronic exposure to malathion at larval stage of these tadpoles can also affect the performance of locomotion in froglets. Therefore, the tadpoles of Fejervarya limnocharis were exposed to sub-lethal concentrations of commercial grade malathion to investigate their jump performance post metamorphosis.

\section{Materials and Methods}

Study material: Free feeding tadpoles of $F$. limnocharis were collected from a natural stream ( $13^{\circ} 47^{\prime} 33.05^{\prime \prime} \mathrm{N}, 75^{\circ} 37^{\prime} 7.97^{\prime \prime} \mathrm{E}$; Alt: 662 m) near Kuvempu University campus, Karnataka, India. The stream originates and flows through Bhadra Wildlife Sanctuary and is devoid of any agricultural activity. The tadpoles were collected using dip net and immediately after collection, tadpoles were placed in an inert plastic container with habitat water. The containers were transferred to laboratory and released into small tank (45 I) containing aged tap water (temperature $24.75 \pm 0.26^{\circ} \mathrm{C}$ ) and allowed to acclimatize to the laboratory conditions for two days. The developmental stage of tadpoles was confirmed according to Gosner (1960) method of classification and they were found to be in stage 25. At this stage, the tadpoles are free feeding and at the beginning of freeswimming state. Further, their length and biomass were recorded. The total length of tadpoles was measured with a digital callipers (Tresna, EC 16, resolution $0.01 \mathrm{~mm}$ ), while the weight was measured on a digital weighing scale (Make: Ohaus pioneer; Precision: $0.0001 \mathrm{~g}$ ). The total length of 25 randomly selected tadpoles ranged between 7 and $9 \mathrm{~mm}$ and the body mass ranged between 2.1 and $12.2 \mathrm{mg}$, respectively.

Treatment schedule : Commercial grade malathion (AI 50\%) was used as a test chemical. The pesticide concentrations of the commercial grade malathion was confirmed by HPLC and was found to be between 46 and $51 \%$. Following the method of Finney (1971) with modifications according to Gurushankara et al. (2003), LC $_{50}$ of malathion on this specie was estimated. The 96hour $\mathrm{LC}_{50}$ for $F$. limnocharis was estimated to be $12267 \mu \mathrm{g}$ malathion $\mathrm{I}^{-1}$. After estimating $\mathrm{LC}_{50}$, the present experiment was conducted two times in a laboratory mesocosm made of inert circular polythene containers (height: $18 \mathrm{~cm}$, radius: $24 \mathrm{~cm}$ ) filled with 6.6 I of aged tap water, in which 6 tadpoles were introduced. The tadpoles were fed with boiled spinach ad libitum and aerated for 30 min every day. Randomly selected tadpoles having Gosner 25 stage were exposed to three concentrations of malathion representing $1 / 10$ th, $1 / 5$ th and $1 / 2$ of $L_{50}$ concentrations (i.e. 1/10th of $L_{50}=1226 \mu \mathrm{g}$ malathion $I^{-1}, 1 / 5$ th of $L_{50}=2453 \mu \mathrm{g}$ malathion $\mathrm{I}^{-1}$ and $1 / 2$ of $\mathrm{LC}_{50}=6133 \mu \mathrm{g}$ malathion $\mathrm{I}^{-1}$ respectively) with a control in triplicates. The $\mathrm{pH}$ and dissolved oxygen in the experimental media ranged between $6.3-7.1$ and $7.5-9.3 \mathrm{mgl}^{-1}$ respectively. The total experimental duration was 52 days. The water level, feeding schedule and other experimental conditions were maintained uniformly for all the treatment groups, except for the concentration of malathion. To keep an environmentally 
realistic condition, water was not changed in the container during the experimental period. However, water in each container was aerated for 30 min per day. The survival rate of tadpoles during the experiments in control group ranged between 98 and 100\%, while it was 93 and $95 \%, 88$ and $90 \%, 71$ and $75 \%$, respectively, for $\mathrm{LC}_{5}, \mathrm{LC}_{10}$ and $\mathrm{LC}_{25}$ concentration treated groups. By the time when all tadpoles of the control group emerged as metamorphs, $39 \%, 28 \%$ and $14 \%$ of the tadpoles of $\mathrm{LC}_{5}, \mathrm{LC}_{10}$ and $\mathrm{LC}_{25}$ treatment concentrations had emerged as metamorphs. After these tadpoles reached Gosner stage 42, they were taken out of the mesocosm and raised separately until stage 45 . The Snout-Vent-Length (SVL), Hind limb length (HLL) were measured with a calliper (Make: Tresna) and body mass (BM) was recorded on a electronic Balance (make: Ohaus Pioneer PAG214C, precision: $0.0001 \mathrm{~g}$ ). Followed by this, each metamorph were subjected to jumping performance. The metamorphs were made to jump on rough surface by prodding gently at the vent using a smooth paint brush. This performance was repeated six times. The distance jumped, and time taken for each jump was recorded for six consecutive attempts. The jumping performance was carried out following the methods of Zug (1985).

Acetylcholinesterase activity : Acetylcholinesterase (AChE) activity was estimated in the thigh muscles of metamorphs (Gosner stage 46) from each treatment and control group, following the method of Ellman et al. (1961) with modifications according to Hill (1988).

Statistical analyses : SPSS (ver.20) was used for computation of data. For all the statistical analyses, the average values for each parameter of the two experiments. Prior to subjecting the data for statistical analyses, the data were checked for normality. Analyses of Variance (ANOVA) with Tukey-Kramer Post hoc test was used to evaluate the significant differences between the data of SVL, BM and jumping distances (as proportional to their hind limb length) recorded from metamorphs emerged from control group and pesticide treated group. Karl-Pearson Correlation co-efficient was used to test the relationship between hind limb of the metamorphs and jumping distance. The $p<0.05$ was considered as significant.

\section{Results and Discussion}

The SVL of metamorphs did not show considerable differences among the treatment groups, $\left(F_{3,21}=2.53, p=0.084\right)$ (Table 1). The wet body mass (mg) of the metamorphs in control was low compared to the treatment groups, however the differences between them were insignificant $\left(F_{3,21}=1.156, p=\right.$ 0.354). Like SVL, the hind limb length did not show significant difference between them $\left(F_{3,21}=2.48, p=0.089\right)$, however, jumping distance showed a clear increase with concentration of malathion $(r=0.96, p=0.036)$ and differences between jumping distance at different treatment were significant $\left(F_{3,21}=11.41, p=\right.$ 0.0001). Further, as the SVL increased, the body mass of the metamorphs also increased $(r=0.97, p=0.02)$. The hind limb length and SVL are believed to be determining factor for jumping performance of frogs (Rand, 1952). The jumping distance as proportional to hind limb length (jumping distance/ hind limb length) was $7.650,7.109,7.948$ and 12.6 for $0 \mu \mathrm{g}, 1226 \mu \mathrm{g}, 2453$ $\mu \mathrm{g}$ and $6133 \mu \mathrm{g}$ malathion $\mathrm{l}^{-1}$. Similarly, the jumping distance as a proportion to SVL (jumping distance/SVL) was 7.47, 7.0, 8.007 and 12.6 respectively. But neither hind limb length nor SVL correlated to their corresponding proportion of jumping distances $(r=0.15, p=0.71$ and $r=0.16, p=0.837)$. The AChE activity in the thigh muscle of froglets emerged from control group $(0 \mu \mathrm{g}$ malathion ${ }^{-1}$ ) was found to be $0.0001511 \mathrm{mmol} \mathrm{min}^{-1} \mathrm{~g}^{-1}$ whereas in the $1226 \mu \mathrm{g}, 2453 \mu \mathrm{g}$ and $6133 \mu \mathrm{g}$ malathion $\mathrm{I}^{-1}$ treatment groups, it was $0.0001656,0.0001616$ and $0.0002394 \mathrm{mmol} \mathrm{min}^{-1} \mathrm{~g}^{-1}$, respectively. A similar increase in $A C h E$ was observed in tadpoles of Odontophrynus americanus exposed to insecticide pyriproxyfen (Lajmonovich et al., 2019). The survival of froglets with malathion concentration showed a significantly strong correlation $(r=-0.991, p=0.009)$. The results revealed that the jumping distance of froglets increased with increasing concentration of malathion $(r=-0.938, p=0.062)$. We suspect this to be the result of larval density. Larval density is known to affect

Table 1: Morphometric measurements, AChE content and jumping distance of froglets treated at different concentrations of malathion at their larval stage

\begin{tabular}{|c|c|c|c|c|c|}
\hline \multirow[b]{2}{*}{ Parameter } & \multicolumn{5}{|c|}{ Treatment Groups } \\
\hline & Control & $\begin{array}{l}\mathrm{LC}_{5}(1226 \mu \mathrm{g} \\
\left.\text { malathion } \mathrm{I}^{-1}\right)\end{array}$ & $\begin{array}{l}\mathrm{LC}_{10}(2453 \mu \mathrm{g} \\
\left.\text { malathion I } \mathrm{I}^{-1}\right)\end{array}$ & $\begin{array}{l}\mathrm{LC}_{25}(6133 \mu \mathrm{g} \\
\left.\text { malathion I }{ }^{-1}\right)\end{array}$ & $\begin{array}{l}\text { Significance } \\
\text { (F and } p)\end{array}$ \\
\hline Snout-Vent length $(\mathrm{mm})$ & $12.9 \pm 1.09$ & $13.9 \pm 0.63$ & $13.4 \pm 0.55$ & $13.6 \pm 0.27$ & $\begin{array}{l}F_{3,21}=2.53 \\
p=0.084\end{array}$ \\
\hline Wet body mass (mg) & $205.2 \pm 32.64$ & $251.8 \pm 63.00$ & $231.5 \pm 41.2$ & $231.5 \pm 66.12$ & $\begin{array}{l}F_{3,21}=1.156 \\
p=0.354\end{array}$ \\
\hline Hind limb length (mm) & $12.6 \pm 1.09$ & $13.7 \pm 1.03$ & $13.5 \pm 0.87$ & $13.6 \pm 0.55$ & $\begin{array}{l}F_{3,21}=2.48 \\
p=0.089\end{array}$ \\
\hline Jumping distance (mm) & $96.4 \pm 24.39$ & $97.4 \pm 33.20$ & $107.3 \pm 21.57$ & $171.6 \pm 9.47$ & $\begin{array}{l}F_{3,21}=11.41 \\
p=0.0001\end{array}$ \\
\hline $\begin{array}{l}\text { Acetylcholinesterase } \\
\left(\mathrm{mmol} \mathrm{min}^{-1} \mathrm{~g}^{-1}\right)\end{array}$ & $\begin{array}{l}0.0001511 \pm 0.00 \\
0195\end{array}$ & $\begin{array}{l}0.0001656 \pm 0.00 \\
00372\end{array}$ & $\begin{array}{l}0.0001616 \pm 0.00 \\
00093\end{array}$ & $\begin{array}{l}0.0002394 \pm 0.00 \\
01103\end{array}$ & $\begin{array}{l}F_{3,21}=0.41 \\
p=0.7502\end{array}$ \\
\hline
\end{tabular}


the size at metamorphosis and jump distance (Wilbur, 1987; John-Alder and Morin, 1990; Tejedo et al., 2000). Because of the reduced larval density due to malathion, the tadpoles in the higher treatment groups experienced lesser competition from fellow individuals and gained more resources. This is further supported by gain in body mass among the malathion treated groups as compared to control (Table 1). A similar observation was made by Gurushankara et al. (2007) wherein at higher concentrations of malathion, the bodymass of tadpoles increased after $1500 \mu \mathrm{g}$ malathion ${ }^{-1}$ treatment group. They also attributed the higher value of $\mathrm{LC}_{50}$ to probable resistance acquired by the species to malathion. Further, malathion degradation is dependent on several factors, such as $\mathrm{pH}$, temperature, light and response of tadpoles varies with presence of other biological stressor with pesticide like malathion (Mulla et al., 1981; Relyea, 2004). Accordingly, the acetylcholinesterase activity in the thigh muscle of froglets increased in a dose-dependent manner. A significantly strong correlation was noted between AChE activity and jumping distance $(r=0.981, p=0.019)$. Since the experiment lasted for 52 days, it is presumed that malathion in the treatment groups degraded with time or tadpoles recovered from malathion stress as observed in fishes (Ansari and Kumar, 1984) and toads (De Castro et al., 1991).

Chemical contaminants are known to alter the animal behaviour, therefore the effect of contaminants and pesticides on animal behaviour is considered important aspect as they contribute to determine the status of ecological community (Weis et al., 2001; Zala and Penn, 2004). Malathion is the most widely used insecticide in India (Gurushankara et al., 2007), however, there are only few studies examining the impacts of malathion on the behaviour of tadpoles and adults (Fordham et al., 2001), food consumption (Gurushankara et al., 2007), swimming behaviour (Webb and Crain, 2006), and activity (Mackey and Boone, 2009). The frog jump is considered as reliant to hind limb length and strength (Rand, 1952; Wilson et al., 2000; Azizi and Roberts, 2010). Malathion being an acetylcholine inhibitor can cause paralyses and inhibit growth (Witter and Gaines, 1963; Ding et al., 2017). Therefore, we anticipated that increased malathion exposure could result in reduction of jumping distance among the survival. But the results revealed a consistent increase in jumping distance with increased malathion concentrations.

In anurans, jumping performance is considered as an indicator of healthy status of the animal (Rand, 1952). Many insecticides like endosulfan are known to interfere with foraging and locomotion of anurans (Preud'homme et al., 2015). Gray treefrogs when exposed to $0.1 \mathrm{mg} \mathrm{l}^{-1}$ carbaryl showed increased locomotor activity by 3 \% (Relyea and Edwards, 2010). In a meta-analysis, Rohr and McCoy (2010) observed that 12 out of 13 studies showed elevated activity to atrazine among fish and amphibians. In rainbow trout, exposure to AChE inhibitor showed hyperactivity (Beauvais et al., 2000) and in salamander such exposure did not show any significant changes in their behaviour (Baker, 1985). In other neurotoxic chemical exposure (neonicotinoids), Lee-Jenkins and Robinson (2018) found no considerable difference in locomotor performance. On the contrary, in the present study the neurotoxic chemical (Malathion) had produced clear increase in jumping performance at higher concentrations. This could be due to short half-life period of malathion, which might have degraded, allowing only small quantity to interact with tadpole. Further, exposure to sub lethal concentrations of commercial grade malathion appears to produce concentration dependent effects on the survival of tadpoles. As a result of the toxic action of malathion, the larval density decreased with the increasing malathion concentration. Lower larval density could have reduced the competition among the tadpoles and resulted in increased size of the metamorphs. This increased the availability of space and resources. Since the exposure was a static non-renewal type, which lasted for $\sim 50$ days, the concentration of malathion might have decreased over the time. With the decreasing larval density and degradation in malathion with time, the acetylcholinesterase activity in the larvae might have recovered. As a result, the metamorphs showed an increased size, increased acetylcholinesterase activity, and increased jumping performance. These chain of events however warrant a detailed investigation.

\section{Acknowledgments}

This work is a part of $\mathrm{Ph}$. D research programme of $\mathrm{Mr}$. Krishna Kulkarni with the permission (KU/AC-2:332:3101:201617) to carry out the present experiment and avail reaserch facility at the Department of Environmental Science, Kuvempu University, Karnataka, India.

\section{References}

Ansari, B.A. and K. Kumar: Malathion toxicity: In-vivo inhibition of acetylcholinesterase in the fish Brachydanio rerio (cyprinidae). Toxicol. Lett., 20, 283-287 (1984).

Azizi, E. and T.J. Roberts: Muscle performance during frog jumping: Influence ofelasticity on muscle operating lengths. Proc. R. Soc. London, B., 77, 1523-1530 (2010).

Baker, K.N.: Laboratory and field experiments on the responses of twospecies of woodland salamanders to malathion treated substrates. Arch. Environ. Contam. Toxicol., 14, 685-691 (1985).

Beauvais, S.L., S.B. Jones, S.K. Brewer and E.L. Little: Physiological measures of neurotoxicity of diazinon and malathion to larval rainbow trout (Oncorhynchus mykiss) and their correlation with behavioral measures. Environ. Toxicol. Chem., 19, 1875-1880 (2000).

Ding, Q., S. Fang, X. Chen, Y. Wang, J. Li, F. Tian, X. Xu, B. Attali, X. Xie and Z. Gao: TRPA1 channel mediates organophosphate-induced delayed neuropathy. Cell Discovery, 3, 17024 (2017).

David, M. and R.M. Kartheek: Malathion acute toxicity in tadpoles of Duttaphrynus melanostictus, morphological and behavioural study. J. Basic Appl. Zool., 72, 1-7 (2015).

De Castro, A.C.C., E.A. Rosenbaum and A.M.P. De D'Angelo: Effect of malathion on Bufo arenarum Hensel development-l: Esterase inhibition and recovery. Biochem. Pharmacol., 41, 491-495 (1991).

Ellman, G.L., K.D. Courtney, V. Andres and R.M. Featherstone: A new and rapid colorimetric determination of acetylcholinesterase activity. Biochem. Pharmacol., 2, 88-95 (1961).

Finney, D.J.: Probit Analysis. $3^{\text {rd }}$ Edn., Cambridge University Press, Cambridge (1971).

Fordham, C.L., J.D. Tessari, H.S. Ramsdell and T.J. Keefe: Effects of 
malathion on survival, growth, development and equilibrium posture of bullfrog tadpoles (Rana catesbeiana). Environ. Toxicol. Chem., 20,179-184 (2001).

Gosner, K.L.: A simplified table for staging anuran embryos larvae with notes on identification. Herpetologica, 16, 183-190 (1960).

Gurushankara, H.P., S.V. Krishnamurthy and V. Vasudev: Effects of malathion on survival, growth and food consumption of Indian cricket frog (Limnonectus limnocharis) tadpoles. Arch. Environ. Contam. Toxicol., 52, 251-256 (2007).

Gurushankara, H.P., V. Vasudev and S.V. Krishnamurthy: Estimation of acute toxicity of malathion insecticides on tadpoles and adults of Rana (Limnonectus limnocharis. Indian J. Comp. Anim. Physiol., 21, 48-54 (2003).

Hegde, G. and S.V. Krishnamurthy: Analysis of health status of the frog Fejervarya limnocharis (Anura: Ranidae) living in rice paddy fields of Western Ghats, using body condition factor and AChE content. Ecotoxicol. Environ. Contam., 9, 69-76 (2014).

Hill, E.F.: Brain cholinesterase activity of apparently normal wild birds. J. Wildl. Dis., 24, 51-61 (1988).

John-Alder, H.B. and P.J. Morin: Effects of larval density on jumping ability and stamina in newly metamorphosed Bufo woodhousil fowleri. Copeia, 1990, 856-860 (1990).

Josende, M.E., A.M. Tozetti, M.T. Alalan, V.M. Filho, S. da Silva Ximenez, F.M.R. da Silva Júnior and S.E. Martins: Genotoxic evaluation in two amphibian species from Brazilian subtropical wet lands. Ecol. Indic., 49, 83-87 (2015).

Krishnamurthy, S.V. and G.R. Smith: Growth, abnormalities, and mortality of free feeding tadpoles of American toad Bufo americanus exposed to combination of malathion and nitrate. Environ. Toxicol. Chem., 29, 2777-2782 (2010).

Krishnamurthy, S.V., D. Meenakumari, H.P. Gurushankara and R.A. Griffiths: Effects of nitrate on feeding and resting of tadpoles of Nyctibatrachus major (Anura: Ranidae). Australas. J. Ecotoxicol., 12, 123-127 (2006).

Lajmanovich, R.C., P.M. Peltzer, C.S. Martinuzzi and C.L. Colussi: Insecticide pyriproxyfen (Dragòn $囚$ ) damage bio-transformation, thyroid hormones, heart rate and swimming performance of Odontophrynus americanus tadpoles. Chemosphere, 220, 714-722 (2019).

Lal, B., M.K. Sarang and P. Kumar: Malathion exposure induces the endocrine disruption and growth retardation in the catfish, Clarias batrachus (Linn.). Gen. Comp. Endocrinol., 181, 139-145(2013).

Lee-Jenkins, S.S.Y. and S.A. Robinson: Effects of neonicotinoids on putativeescape behaviour of juvenile Wood Frogs (Lithobates sylvaticus) chronically exposed as tadpoles. Environ. Toxicol. Chem., 37, 3115-3123 (2018)

Mackey, M.J. and M.D. Boone: Single and interactive effects of malathion, overwintered green frog tadpoles, and cyanobacteria on gray tree frog tadpoles. Environ. Toxicol. Chem., 28,637-643 (2009).

Mann, R.M., R.V. Hyne, C.B. Choung and S.P. Wilson: Amphibians and agricultural chemicals: Review of the risks in a complex environment. Environ. Pollut., 157, 2903-2927 (2009).

Mulla, M.S., L.S. Mian and J.A. Kawecki: Distribution, transport and fate of the insecticides malathion and parathion in the environment. In: Residue Reviews. (Eds.: F.A. Gunther and J.D. Gunther). Vol. 81, pp. 1-172 (1981).

Nataraj, M.B. and S.V. Krishnamurthy: Effects of combinations of malathion and cypermethrin on survivability and time of metamorphosis of tadpoles of Indian cricket frog (Fejervarya limnocharis). J. Environ. Sci. HIth., 47, 67-73 (2012).

Preud'homme, V., S. Milla, V. Gillardin, E. De Pauw, M. Denoë and P. Kestemont: Effects of low dose endosulfan exposure on brain neuro-transmitter levels in the African clawed frog Xenopus laevis. Chemosphere, 120, 357-364 (2015).

Rand, A.S.: Jumping ability of certain anurans, with notes on endurance. Copeia, 1952, 15-20 (1952).

Rao, A.S. and R.R. Pillala: The concentration of pesticides in sediments from Kolleru Lake in India. Pest. Manage. Sci., 57, 620-624( 2001).

Relyea, R.A. and K. Edwards: What doesn't kill you makes you sluggish: How sublethal pesticides alter predator-prey interactions. Copeia, 10, 558-567 (2010).

Relyea, R.A.: Synergistic impacts of malathion and predatory stress on six species of North American tadpoles. Environ. Contam. Toxicol., 23, 1080-1084 (2004).

Relyea, R.A.: A cocktail of contaminants: How mixtures of pesticides at low concentrations affect aquatic communities. Oecologia, 159, 363-376 (2009).

Rohr, J.R. and K.A. McCoy: A qualitative meta-analysis reveals consistent effects of atrazine on freshwater fish and amphibians. Environ. Hith. Perspect., 118, 20-32 (2010).

Sankararamakrishnan, N., A.K. Sharma and R. Sanghi: Organochlorine and organophosphorous pesticide residues in ground water and surface waters of Kanpur, Uttar Pradesh, India. Environ. Int., 31, 113-120 (2005).

Shuman-Goodier, M.E. and C.R. Propper: A meta-analysis synthesizing the effects of pesticides on swim speed and activity of aquatic vertebrates. Sci. Total Environ., 565, 758-766 (2016).

Sievers, M., R. Hale, K.M. Parris, S.D. Melvin, C.M. Lanctôt and S.E. Swearer: Contaminant-induced behavioural changes in amphibians: Ameta-analysis. Sci. Total Environ., 693, 133-570 (2019).

Söffker, M. and C.R. Tyler: Endocrine disrupting chemicals and sexual behaviors in fish a critical review on effects and possible consequences. Crit. Rev. Toxicol., 42, 653-668 (2012).

Tejedo, M., R.D. Semlitsch and H. Hotz: Covariation of morphology and jumping performance in newly metamorphosed water frogs: Effects of larval growth history. Copeia, 2, 448-458 (2000).

Vasconcelos, A.M., M.A. Daam, L.R.A. dos Santos, A.L.M. Sanches, C.V.M. Araujo and E.L.G. Espindola: Acute and chronic sensitivity, avoidance behavior and sensitive life stages of bull frog tadpoles exposed to the biopesticide abamectin. Ecotoxicol., 25, 500-509 (2016).

Venturino, A., E. Rosenbaum, A.C. De Castro, O.L. Anguiano, G. Gauna, T.F. De Schroeder and A.M.P. De D'Angelo: Biomarkers of effect in toads and frogs. Biomarkers, 8, 167-186 (2003).

Webb, C.M. and D.A. Crain: Effect of ecologically relevant doses of malathion on developing Xenopus laevis tadpoles. Bios., 77, 1-6 (2006).

Weis, J.S., G. Smith, T. Zhou, C. Santiago-Bass and P. Weis: Effects of contaminants on behavior: biochemical mechanisms and ecological consequences. Bio. Sci., 51, 209-217 (2001).

Wilbur, H.M.: Regulation of structure in complex systems: Experimental temporary pond communities. Ecology, 68, 1437-1452 (1987).

Wilson, R.S., C.E. Franklin and R.S. James: Allometric scaling relationships of jumping performance in the striped marsh frog Limnodynastes peronii. J. Exp. Biol., 203, 1937-1946 (2000).

Witter, R.F. and T.B. Gaines: Relationship between depression of brain or plasma cholinesterase and paralysis in chickens caused by certain organic phosphorus compounds. Biochem. Pharmacol., 12, 1377 $1386(1963)$

Zala, S.M. and D.J. Penn: Abnormal behaviours induced by chemical pollution: A review of the evidence and new challenges. Anim. Behav., 68, 649-664 (2004).

Zug, G.R.: Anuran locomotion: Fatigue and jumping performances. Herpetologica, 41, 188-194 (1985). 